\title{
The European Financial System in Limelight
}

\author{
Noureen Adnan and Syed Jawad Hussain Shahzad
}

\begin{abstract}
Efficient use of resources depends on better allocation through financial systems. Development of financial systems can be measured through the performance of banks, financial markets and insurance companies. This paper identifies several key attributes to measure the level of financial development in Europe using data from 1990 to 2011. First, an index is constructed by employing the method of Principal Component Analysis to measure the strength of financial systems in European countries. Second, based on relative raking a comparison is made for better interpretation of results in European countries. The top five countries include Switzerland, United Kingdom, Netherlands, Spain and Germany. The results of this study can be helpful to assess the relative strength of European economies and frame future policies to promote efficiency of financial systems.
\end{abstract}

Index Terms-Europe, financial systems, principal component analysis.

\section{INTRODUCTION}

Development of financial systems is considered crucial to achieve economic growth. It helps to allocate the resources to their productive use. Levine [1] highlighted the role of financial systems for promoting economic growth. Development of financial systems reduces information asymmetry leading towards enhanced investor's interest [2]. Investors trust results in precise decision making through better forecast of prospective profitable investment opportunities. Availability of financial services mainly depends on the efficiency of the financial institutions operating in the country. Diversification benefits results from the improved access to information and use of this information in developed financial markets. Financial institutions critically evaluate and identify businesses with profitable prospects. This evaluation helps in efficient fund allocation and promotes economic activities. Stock markets and the financial institution like banks provide opportunities to the one having saving in better placements and help borrowers in finding funds at favorable rates. These favorable rates are determined by the level of competition in the market. Strong financial systems promote fair play in the economy with access to information. Financial institutions also play the role of monitoring and scrutinizing the performance of investments and its management. The financial systems while enabling investors to diversify also encourage them to invest in high return ventures. To gain investors' trust as well as investments, financial intuitions

Manuscript received April 1, 2014; revised July 9, 2014.

The authors are with the Department of Management Sciences, COMSATS Institute of Information Technology, Islamabad PC-44000, Pakistan (e-mail: norinadnan@comsats.edu.pk, jawadhussain@vcomsats.edu.pk). work hard to lower the transaction cost and trade barriers. All these measures taken to facilitate businesses lead to economic activities, development and growth. The poor functioning of financial systems can hit the economy alternatively. If there are high transaction costs, information asymmetry and management issues in financial system, the mechanism loses investor's trust that results stagnant growth, less economic activities and finally may lead economy to crash. Although the importance of financial systems cannot be over looked; literature on measures of financial system is not clear. Measures used to gauge financial development like real interest rate and broad money to Gross Domestic Product (GDP) can result in misleading conclusions [3]. Financial liberalization as well as domestic level public borrowing is overlooked and thus conclusions drawn on such indicators do not present the actual level of financial development. Literature identifies many indicators of financial development such as the size, activity, expansion, structure, efficiency and foreign direct investment. These measures are used to gauge the activities and performance of banks, financial markets and insurance institutions.

This paper, therefore, aims to measure level of financial system performance in European countries. Banking, stock market and insurance companies' indicators of financial performance are collected for the analysis. Principal component analysis is used to formulate a unique index of financial development. Significant information can easily be extracted through this method. It is helpful in revealing the hidden composition in any data set [4]. A meaningful index is formulated through complex and multidimensional essentials of financial improvement. It has helped to re-frame the variables by reducing noise so that a single measure of financial development is achieved. Rest of the paper is organized as follows: Section II highlights literature and identifies research gap. Section III is about data used for analysis and Section IV explains the methodology. Results are discussed in Section V. Section VI provides the conclusion on financial systems.

\section{LITERATURE REVIEW}

Better functioning financial systems allocate capital based more on the expected quality of the project and entrepreneur and based less on the accumulated wealth and social connections of the entrepreneur. Under many conditions, therefore, better functioning financial systems that overcome market frictions will more effectively identify and fund the most promising firms and not just funnel credit to large companies and rich individuals. Thus, to develop informative proxies of financial development, it is useful to move beyond financial depth and also include indicators of financial access - the degree to which the public can access financial 
services. As with the other measures, both financial institutions and financial markets are to be examined. Many measures and techniques are used in literature to explain the financial strength of institutions. This section covers main attributes of financial development and contributions made by the researchers to measure the depth of financial systems. Banks as an institution play vital role in financial development of a country. Banks channelize the saving from lenders to the borrowers. Credits are efficiently allocated to the private sector and potential businesses which expands industrial productivity and result in a better economy with growth potentials. The allocation of credit to potential positive net present value (NPV) projects enables creativity and confidence of prospective businesses. Banks saves its customers from liquidity risk by offering long term investments [5].

Financial development can also be measured by studying the financial markets operating in a country. Just like any other financial intuitions, role of stock markets in an economy is critical. They provide a common place for buying and selling and promote trade. Availability of funds and trading enhances activity in the economy. However, liquidity of financial products is the main attribute in building investors interest. Stock markets having liquidity help firms to access the required capital easily [6]. Ease and access to funds can be made possible by the development of stock markets. Development of stock market is considered a step towards better financial development. The role of non-banking institution cannot be overlooked while identifying the measures of financial systems and their performance. These intuitions are asset management firms, hedge funds, pension funds and insurance companies. These intuitions provide different financial instruments and products but unlike banks do not accept the demand deposits. Non-banks compete with the traditional banks for the lending opportunities. Without affecting the money supply they enhance the credit in markets through cheap borrowing. Rating play major role for competitive excellence and also determines their performance [7]. Competition among banking and non-banking institutions is considered healthy and results in financial development. Saci and Holden [8] in a study to analyze the determinants of financial development used principal component analysis. They have used ten different proxies as development indicators of financial intermediaries.

A country based comparison to examine the role of different factors of financial development is done by Huang [9]. To measure the level of financial development PCA and Bayesian model averaging (BMA) model is applied using variables like banks liquid liabilities, banks overhead costs, net interest margins, stock market capitalization, total values traded and turnover ratio. Antzoulatos et al., [2] constructed financial development indices for banks, financial institutions and stock market. Studies of King and Levine [1], Neusser [10], Demetriades et al, [11], Rousseau and Wachtel [12], and Levine and Zervos [13] highlighted numerous measures of financial depth. Literature identifies two different set of measures. The first set measures financial development through indicators of access, size and depth of financial systems. Legal, political conditions for business and financial stability constitute the second group of measures. Characteristics of institutions and overall environmental conditions are measured through this second group of variables and are qualitative in nature.

\section{DATA}

This study utilizes the secondary data obtained from World Bank development indicators, International financial statistics and Beck et al, data set ${ }^{1}$. Subject to data availability, our final sample consists of 18 countries from European economies. The annual measures are from 1990 to 2011. To accurately measure the depth of financial systems, the financial development indexing is done based on Saci and Holden [8] criterion. The main differences between the current study and Saci are, first an enlarged data set with thirteen different financial sector components including size, activity, efficiency, expansion and structure are used to construct an index. Second, most recent data sets from 1990 to 2011 in contrast to Saci and Holden [8] i.e. from 1988 to 2001. Moreover, this index mainly focuses the European economies with 18 countries of Europe to form financial development index whereas Saci has employed 30 countries from all over the world. This paper only utilizes observable outcomes of financial development since the qualitative measures are highly time invariant. Table I shows the characteristics and measures used to examine the level of financial systems.

TABLE I: SAMPLE FINANCIAL INSTITUTIONS AND MEASURES WITH REFERENCES

A. Banks

1) To capture size, Depth \& liquidity we used liquid liabilities ratio to GDP (M3 to GDP) [1], [9], [12] and [14]. (LL)

2) Activities are measured through private credit ratio of deposit money banks to GDP [13]. (CR1)

3) To differentiate between private and public sector credits ratio of credit issued to the private sector by deposit money banks and other financial institutions to GDP is deployed. [1] and [14]. (CR2)

4) Expansion is gauged through ratio of commercial bank assets to commercial plus central bank assets [5]. (BA)

5) Structure is measured by bank's concentration ratio of the three biggest banks assets to the assets of all commercial banks in the system. (BC)

6) Net interest margins and overhead costs are used for efficiency. [1], [9] and [14]. (IM) \& (BO)

B. Stock Markets

1) Size is captured through stock market capitalization as percentage of GDP. (SC)

2) Activities are measured as ratio of stock market value traded as a percentage of GDP. (ST)

3) Efficiency/ liquidity on a macroeconomic scale through stock market turnover ratio. (SV)

C. Insurance Companies

1) Activity is measured through life insurance premium volume as a share of GDP and non life insurance premium volume as a share of GDP. (LI) \& (NL)

\section{Methodology - Principal COMPONENT ANALYSIS}

The method of principal component reduces the dimension

${ }^{1}$ A New Database on Financial Development and Structure [14]. 
of large data set while retaining the maximum variation. It converts the large data set in new variables termed as principal components. Moreover, these unique variables resulting from PCA extraction are uncorrelated which provides better interpretation during analysis. First few components (principal) provide maximum explaining power of the original exhaustive data set [15]. The analysis is used to detect the structural relationship among the variables understudy. An orthogonal transformation converts the observations of correlated variables into linearly unrelated components. Extracted components are the weighted average of the original variables. In this study, first principal component is therefore the approximation of financial development [16]. This method provides strength of constructing index of financial development and formulated new principal components for financial development using data set of European countries.

\section{RESULTS}

A single parameter is constructed to rank the financial development for European countries i.e. EF index. Results of ranking are shown in Table II.

\begin{tabular}{|c|c|c|c|c|c|c|}
\hline Rank & Country & Mean & Min. & Max. & Std. Dev. & Obs. \\
\hline 1 & Switzerland & 4.3255 & 2.118 & 7.316 & 1.365 & 21 \\
\hline 2 & United Kingdom & 2.7501 & 1.028 & 5.724 & 1.507 & 21 \\
\hline 3 & Netherlands & 2.1971 & -1.863 & 5.416 & 1.797 & 22 \\
\hline 4 & Spain & 0.8979 & -1.570 & 6.069 & 2.218 & 22 \\
\hline 5 & Germany & 0.7452 & -0.410 & 1.576 & 0.616 & 20 \\
\hline 6 & France & 0.5308 & -0.539 & 2.347 & 0.830 & 22 \\
\hline 7 & Denmark & 0.4689 & -1.712 & 4.662 & 2.019 & 20 \\
\hline 8 & Belgium & 0.3175 & -1.504 & 2.404 & 0.998 & 21 \\
\hline 9 & Portugal & 0.2548 & -2.283 & 2.613 & 1.483 & 22 \\
\hline 10 & Finland & 0.2438 & -0.678 & 1.745 & 0.743 & 22 \\
\hline 11 & Austria & 0.0784 & -0.418 & 0.879 & 0.340 & 22 \\
\hline 12 & Italy & -0.6173 & -2.237 & 2.630 & 1.382 & 22 \\
\hline 13 & Norway & -0.8704 & -1.287 & -0.471 & 0.238 & 19 \\
\hline 14 & Czech Republic & -1.7199 & -2.070 & -1.039 & 0.253 & 19 \\
\hline 15 & Greece & -1.9524 & -3.325 & -0.025 & 1.159 & 22 \\
\hline 16 & Poland & -3.0955 & -4.097 & -1.410 & 0.771 & 18 \\
\hline 17 & Hungary & -3.1633 & -4.420 & -1.784 & 0.861 & 18 \\
\hline 18 & Turkey & -3.9021 & -5.590 & -2.136 & 0.913 & 22 \\
\hline
\end{tabular}

Note: Min, max, std. dev, and obs. represent minimum, maximum, standard deviation and number of observation/ annual data points used for analysis.

TABLE III: RESULTS OF PRINCIPAL COMPONENTS ANALYSIS

\begin{tabular}{|c|c|c|c|c|}
\hline \multicolumn{5}{|c|}{ Eigen values: $($ Sum $=14$, Average $=1)$} \\
\hline Number & Value & Difference & \multicolumn{2}{|l|}{ Proportion } \\
\hline 1 & 5.502 & 3.928 & \multicolumn{2}{|l|}{0.393} \\
\hline 2 & 1.573 & 0.318 & \multicolumn{2}{|l|}{0.112} \\
\hline 3 & 1.255 & 0.176 & \multicolumn{2}{|l|}{0.089} \\
\hline 4 & 1.079 & 0.036 & \multicolumn{2}{|l|}{0.077} \\
\hline 5 & 1.042 & 0.181 & \multicolumn{2}{|l|}{0.074} \\
\hline 6 & 0.860 & 0.124 & \multicolumn{2}{|l|}{0.061} \\
\hline 7 & 0.736 & 0.026 & \multicolumn{2}{|l|}{0.052} \\
\hline 8 & 0.709 & 0.326 & \multicolumn{2}{|l|}{0.050} \\
\hline 9 & 0.382 & 0.041 & \multicolumn{2}{|l|}{0.027} \\
\hline 10 & 0.341 & 0.062 & \multicolumn{2}{|l|}{0.024} \\
\hline 11 & 0.279 & 0.149 & \multicolumn{2}{|l|}{0.020} \\
\hline 12 & 0.130 & 0.046 & \multicolumn{2}{|l|}{0.009} \\
\hline 13 & 0.083 & 0.060 & \multicolumn{2}{|l|}{0.005} \\
\hline \multirow[t]{3}{*}{14} & 0.022 & --- & \multicolumn{2}{|l|}{0.002} \\
\hline & & & \multicolumn{2}{|c|}{ Eigenvectors (loadings) } \\
\hline & $\begin{array}{l}\text { Cumulative } \\
\text { Value }\end{array}$ & $\begin{array}{l}\text { Cumulative } \\
\text { Proportion }\end{array}$ & Variables & PC1 \\
\hline 1 & 5.50 & 0.393 & BA & 0.207 \\
\hline 2 & 7.07 & 0.505 & $\mathrm{BC}$ & 0.086 \\
\hline 3 & 8.33 & 0.595 & $\mathrm{BO}$ & 0.060 \\
\hline 4 & 9.41 & 0.672 & CR1 & 0.387 \\
\hline 5 & 10.45 & 0.746 & CR2 & 0.386 \\
\hline 6 & 11.31 & 0.808 & IM & 0.270 \\
\hline 7 & 12.05 & 0.860 & LI & 0.312 \\
\hline 8 & 12.75 & 0.911 & LL & 0.347 \\
\hline 9 & 13.14 & 0.938 & NL & 0.276 \\
\hline 10 & 13.48 & 0.963 & $\mathrm{SC}$ & 0.328 \\
\hline 11 & 13.76 & 0.983 & ST & 0.171 \\
\hline 12 & 13.89 & 0.992 & SV & 0.308 \\
\hline 13 & 13.97 & 0.998 & & \\
\hline 14 & 14.00 & 1 & & \\
\hline
\end{tabular}

Top countries as ascertained through EF index are Switzerland, United Kingdom, Netherlands, Spain and
Germany. Switzerland stood at the top position in the index with higher mean and maximum value in the index. The financial services and industry of Switzerland ${ }^{2}$ are highly developed. United States (US), Netherlands, Germany and France are its major importers. Swiss National Banks' contributed to economy through zero interest rate policy and prevented currency depreciation after financial crises of 2007-08.

United Kingdom (UK) and Netherland appear second and third most developed financial economies in EF index. Strong financial institutions with favorable trade facilities are prominent features of United Kingdom. After the financial crises of 1992, UK economy improved significantly. However, due to recent 2007-08 financial crisis, it has suffered a decline in growth. In EF index, UK stood second in 18 European countries. Poland, Hungary and Turkey are the least developed economies in Europe. Similar findings can be found in World Fact book regarding these countries. These findings also signify the importance of EF index and thus portray a good financial strength of 18 economies.

The results of principal component analysis are shown in Table III.

The second column shows eigen values for each extracted component. The third column represents the difference between any consecutive eigen values of principal components. Fourth column reports the proportion that is the variation explained by each component. Fifth column presents cumulative variation by adding the variations of

\footnotetext{
${ }^{2}$ Source: World Fact Book (2011)
} 
previous components. Eigen values (variance matrix) are used to extract the principal components. First principal component has the highest cumulative proportion i.e. 0.393 . It can also be interpreted as PC1 has $39.3 \%$ explaining power of total data set. Remaining components add the variation between the unit length combinations (Johnson and Wichern, 1992). Second and third components explain $11.24 \%$ and $8.97 \%$ variation respectively. First four principal components are able to explain $67.22 \%$ of the entire data set. Remaining ten components explain around $30 \%$ of variation. It can easily be inferred from the PCA that first four components may be used as the measure of financial development in Europe based on the sample period of this particular study.

Coefficients of first principal component are shown in the last column. Positive values indicate that PC1 may be used as the overall financial development measure in Europe. Bank activity contributes significantly to the PC1 with 0.387 and 0.386 loadings. Bank expansion (BA) has 0.20 loading in $\mathrm{PC} 1$. Insurance institutions characteristics as measure through LI and $\mathrm{Nl}$ also contributes significantly in PC1. Stock market measures SC and SV have the loadings of 0.328 and 0.308 respectively. First, principal component has approx. $40 \%$ explaining power of whole data set therefore we can infer that banks, stock markets and insurance companies are the vital determinants of European financial systems and the measures used in this study are able to reflect the financial strength in Europe.

In recent years, innovation in financial systems has attracted the investors. As a result, these institutions have attained considerable importance as compared to the economic policies [17]. These findings suggest that financial services are considered very important compared to real sector and savings in these countries are channelized to services industries. Table IV represents the correlation between first four principal components obtained through PCA and indicators of financial services in Europe.

TABLE IV: CORRELATION PC1-PC4 AND FINANCIAL INDICATORS IN

\begin{tabular}{lcccc}
\multicolumn{5}{c}{ EUROPE $(1990-2011)$} \\
Variables & PC1 & PC2 & PC3 & PC4 \\
BA & 0.4845 & 0.2008 & 0.2479 & -0.2735 \\
BC & 0.2015 & 0.0166 & -0.6442 & -0.3356 \\
BO & 0.1402 & 0.5160 & -0.2682 & 0.4472 \\
CR1 & 0.9068 & -0.0147 & 0.1201 & -0.2515 \\
CR2 & 0.9058 & 0.0105 & 0.0585 & -0.2359 \\
IM & 0.6335 & 0.5042 & -0.1727 & 0.1426 \\
LI & 0.7308 & 0.0747 & -0.1310 & 0.2022 \\
LL & 0.8149 & 0.0240 & 0.0298 & -0.0971 \\
NL & 0.6474 & 0.2345 & -0.021 & 0.0645 \\
SC & 0.7688 & -0.2832 & -0.3097 & 0.2500 \\
ST & 0.4000 & -0.6026 & 0.3733 & 0.2708 \\
SV & 0.7219 & -0.5184 & -0.0833 & 0.3107 \\
\hline
\end{tabular}

Correlation analysis also verifies the importance of $\mathrm{PC} 1$ as a whole measure of the sample data set. Except BC and BO, all other measures of financial development show high correlation values. It is evident that all indicators of financial development are positively correlated with EF index i.e. PC1.

\section{CONCLUSION}

T Financial development has been considered a vital player in economic growth of countries. Same is evident through the literature on financial economics. Financial development results from a collective effort through qualitative and quantitative measures. Institutions, policies and factors promote efficient intermediation. This paper attempts to identify the key parameters of financial development in Europe. Twelve indicators of banks, stock markets and insurance intuitions activity, size, expansion and efficiency, for the period 1990 - 2011, have been used to frame the overall picture of financial development. Principal component analysis is utilized to extract a precise measure of financial development and thus EF index is constructed. Switzerland stands first in Europe, United Kingdom and Netherlands are second and third most developed financial systems according to EF index. Turkey has the least developed financial system and has been assigned a negative value as per EF ranking. Results of this paper invite policy makers to rethink some key questions. First, does shifting of economic savings to financial sector instead of real sector lead to crises and failure? Or financial modernization benefits the economy and enhances growth?

This study has potential to incorporate nonfinancial development measures. Advancement in technology and polices in nonfinancial sector and institutions can be incorporated to understand the holistic framework of financial development. Technological advancements lower the transaction costs and affect financial development [18]. Country specific nonfinancial policy issues can also have unique relation and meaning when translated in context of financial development [19].

\section{REFERENCES}

[1] R. Levine and R. King, "Finance, entrepreneurship and growth: theory and evidence," Journal of Monetary Economics, vol. 32, no. 3, pp 513-542, 1993.

[2] C. K. Adjasi and N. B. Biekpe, "Stock market development and economic growth: the case of selected African countries," African Development Review, vol. 18, no. 1, pp. 144-161, 2006.

[3] H. Pill and M. Pradhan, "Financial indicators and financial change in Africa and Asia," International Monetary Fund, 1995.

[4] J. Shlens, A Tutorial on Principal Component Analysis, Systems Neurobiology Laboratory, University of California at San Diego. p. 82, 2005.

[5] R. Levine, "Financial development and economic growth: views and agenda," Journal of Economic Literature, vol. 35, no. 2, pp. 688-726, 1997.

[6] C. T. Antzoulatos and D. Kyriazis, Financial Development and Asymmetric Information, SSRN 1100032, 2008.

[7] D. W. Diamond and P. H. Dybvig, "Bank runs, deposit insurance, and liquidity," The Journal of Political Economy, pp. 401-419, 1983.

[8] K. Saci and K. Holden, "Evidence on growth and financial development using principal components," Applied Financial Economics, vol. 18, no. 19, pp. 1549-1560, 2008.

[9] Y. U. Huang, "What determines financial development?" Discussion Paper. 05/580, University of Bristol, 2005.

[10] K. Neusser and M. Kugler, "Manufacturing growth and financial development: Evidence from OECD countries," Review of Economics and Statistics, vol. 80, no. 4, pp. 638-646, 1998.

[11] P. Demetriades and K. Hussein, "Does financial development cause economic growth? Time-series evidence from 16 countries," Journal of Development Economics, vol. 51, no. 2, pp. 387-411, 1996.

[12] P. L. Rousseau and P. Wachtel, "Financial intermediation and economic performance: historical evidence from five industrialized countries," Journal of Money, Credit and Banking, pp. 657-678, 1998.

[13] R. Levine and S. Zervos, "Stock market development and long-run growth," The World Bank Economic Review, vol. 10, no. 2, pp. 323, 1996.

[14] T. Beck, A. Kunt, and R. Levine, "A new database on the structure and development of the financial sector," The World Bank Economic Review, vol. 14, no. 3, p. 597, 2000. 
[15] Jolliffe, Principal Component Analysis, John Wiley and Sons, Ltd, 2005.

[16] Jackson, "A user's guide to principal components," Wiley-Interscience, 2005.

[17] T. I. Palley, "Financialization: What it is and why it matters (No. 525)." Working papers//The Levy Economics Institute, 2007.

[18] R. C. Merton, "Financial innovation and economic performance," Journal of Applied Corporate Finance, vol. 4, no. 4, pp. 12-22, 1992.

[19] R. Levine, N. Loayza, and T. Beck, "Financial intermediation and growth: causality and causes," Journal of Monetary Economics, vol. 46, no. 1, pp. 31-78, 2000.

Noureen Adnan holds a doctorate degree in financial economics from the Department of Economics, University of Surrey, UK. Previously, she obtained a master degree of science degree in financial economics from Cardiff Business School, Cardiff University, UK. She is a recipient of merit scholarship for MS leading to $\mathrm{PhD}$ by Comsats Institute of Information Technology (GoP). Dr. Noureen also holds a degree in MBA (Finance) with distinction. During her stay in the UK, she received a graduate teaching certificate from London School of Economics and also won the Charles Wallace (UK) fellowship for her outstanding performance in $\mathrm{PhD}$ and leadership abilities amongst the women from developing countries

Dr. Noureen joined the Department of Management Sciences, since inception of CIIT Islamabad campus. Her areas of expertise are investment analysis, portfolio management, econometrics for finance, business mathematics and statistics and research methods both at undergraduate and postgraduate level. She has taught at University of Surrey, UK as part of her doctorate.

Dr. Noureen is a member of Royal Economic Society, UK. A fervent researcher herself Dr. Noureen envisions her future research to explore the relationship between the role of monetary and fiscal policy over the probability of financial crises. It is a point of interest to investigate the role of these policies to stabilise the economy and to examine the association between financial development and the scope for financial crises Considering the recent financial turmoil, it is possible to make crisis prevention policies in order to avoid financial bubbles and crashes in the future.

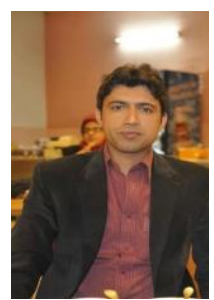

Syed Jawad Hussain Shahzad has recently done his MS degree in finance from COMSATS Institute of Information Technology, Islamabad Pakistan with distinction. $\mathrm{He}$ is also studying Chartered Financial Analyst (CFA) and Financial Risk Management (FRM).

$\mathrm{He}$ is currently a lecturer in the Department of Management Sciences, COMSATS Institute of Information Technology, Virtual Campus Islamabad Pakistan. 